\title{
Kurse Wiener Art
}

_ Ohne Fortbildungen scheint dieser Beruf nicht zu funktionieren - das war mein Eindruck nach den ersten Wochen Physiotherapieausbildung. Der riesige Fortbildungsmarkt erschien mir unüberschaubar. Als das Examen nahte und uns die Lehrer verstärkt ans Herz legten, Manuelle Lymphdrainage direkt nach der Ausbildung zu belegen, waren mir die vielen Kursangebote immer noch suspekt. Eigentlich wollte ich das bisher Gelernte erst einmal anwenden. So entschied ich mich dagegen.

_ Die meisten Mitschüler meldeten sich zum Lymph-Kurs an. Sie hatten Sorge, sonst keinen Job zu bekommen. Ob sie sich für Vodder, Asdonk oder Földi entschieden, überließen sie meist dem Zufall: „Da kann ich zu Hause wohnen“, „dort ist es 100 Euro günstiger“ - waren

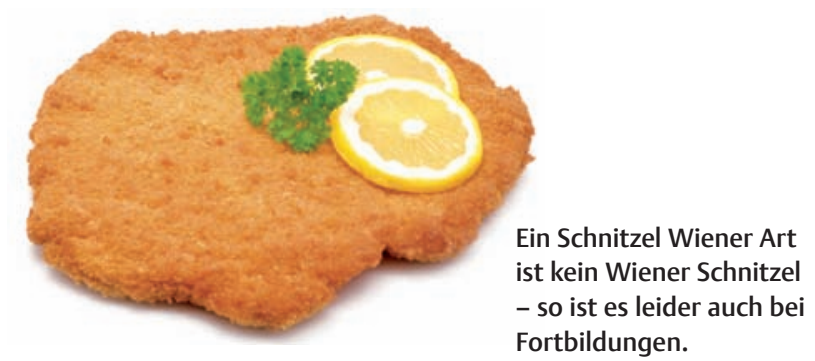
die Argumente. Die Inhalte wurden selten genannt. Möglicherweise zu Recht, weiß ich durch meine Recherche für den Artikel über Manuelle Lymphdrainage (॰ S. 36). Denn Vodder, Asdonk und Földi unterscheiden sich nur minimal voneinander.

- Weiß man die Richtung, weiß man allerdings noch lange nicht, welcher Kursanbieter. Davon gibt es - wie in jedem Bereich in der Physiotherapie - auch in der Manuellen Lymphdrainage unzählig viele. Qualitativ gute wie schlechte. Auf das Problem, dass nicht jede Fortbildung hält, was ihr Name verspricht, machte vor einigen Jahren das McKenzie Institut - das Original - mit ihrem Werbeslogan aufmerksam: „Ein Schnitzel Wiener Art ist kein Wiener Schnitzel.“ Unter die Originale mischen sich Kopien. Welcher Kurs zu welcher Schnitzel-Sorte gehört, ist meist nicht auf den ersten Blick zu erkennen. Und selbst wenn man das Original von der Kopie unterscheiden kann, sagt das noch lange nichts über die Qualität aus.

_ Der Fortbildungsmarkt bleibt undurchsichtig. Dass sich daran dringend etwas ändern muss, ist auch die Meinung eines Lesers (๑ S. 8). Er hat konkrete Ideen, wie man die Manuelle Therapie übersichtlicher gestalten könnte. Sie auch?

Herzlichst, Ihre
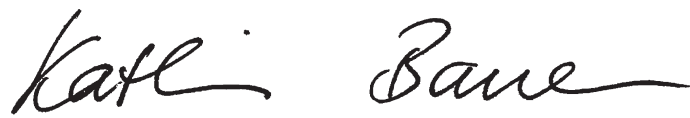

\section{ZU GEWINNEN}

In jeder physiopraxis werden attraktive Gewinne verlost. Möchten Sie einen ergattern, dann klicken Sie unter www.thieme.de/physioonline > „physiopraxis exklusiv“ auf „Gewinnspiel“.

Und das gibt es in dieser Ausgabe zu gewinnen:

Bücher

3-mal „Die Feigheit der Frauen“"

Seite 46

3-mal „Wissenschaft transparent"

Seite 50

und außerdem

12 Paar Aktivstrümpfe

1 Fußball

Seite 39

1 großes Handtuch 